\title{
Investigation and Analysis on the Status of Minor with Double Degree-Taking Inner Mongolia Medical University as an Example
}

\author{
Hu Jiajing ${ }^{1}$ \\ Sanitation Management College of Inner Mongolia Medical \\ University
}

\begin{abstract}
In order to discuss the existing problems in the cultivation of double-degree personnel, this research adopts questionnaire survey to investigate learning motivation, teaching management evaluation, teaching satisfaction degree and other aspects of 123 students with double degree majoring in Public Affairs Administration of Inner Mongolia Medical University. Through data analysis, it points out the problems of students lacking reasonable guidance, unsound award and punishment system, unreasonable specialty structure and course arrangement as well as the loss of teaching supervision mechanism. Meanwhile it also puts forward corresponding suggestions.
\end{abstract}

Keywords-Minor with double degree; Student evaluation; Higher education; Current status investigation

\section{INTRODUCTION}

Since some universities of our country carried out the education pilot for minor in double degree in 1989, many universities have successively joined in the double degree education rank as per their own characteristics, and presented diversified characteristics. Since Inner Mongolia Medical University opened the double degree education of public affairs administration in 2010, students studying it has presented a trend of increase year by year, and the total quantity of students has been increased to the scale of about 70 from about 10 at first, and the school has also increasingly paid attention to the double degree education. Although double degree education has obtained a relatively big progress in the recent years, there are still unfilled publicity explanation and other issues.

Currently, the research on double degree education mainly focuses on normative research, and using qualitative method to study achievements, existing problems and suggestions and countermeasures. Currently, the study holds affirmative altitude towards the education system of double degree, and

\author{
Zhang Nan* \\ Sanitation Management College of Inner Mongolia Medical \\ University. \\ E-mail: skyzn@126.com
}

has great significance to the cultivation of inter-disciplinary talents, but there are also some problems in the meantime: the national team and double degree education work don't have clear political guidance or specific system normalization, and this has made universities fail to form unified cognition in actual operation [1]. Meanwhile, from the perspective of universities, they lack in sound education supervision system and management system [2], the double degree cultivation objective for various schools is single, the talent cultivation mode is not accurately positioned, so the structural lack of talents and other problems occur [3]. The current researches are mostly the qualitative analysis from management and other macroscopic layers, and lack in in-depth quantitative analysis. This research is aimed to understand the current status of double degree through investigating the learning motivation and evaluation of double degree students on teaching management, and the teaching of teachers.

\section{RESEARCH METHODS}

\section{A. Research object}

This research takes the undergraduate double degree students of 2013, 2014 and 2015 Grade Public Affairs Administration in Inner Mongolia Medical University as the research object. Under the precondition of "voluntary participation" and "no secret-ballot investigation", totally 141 questionnaires were issued, and 138 questionnaires were received, and after removing 15 invalid questionnaires with omission conditions, 123 valid questionnaires were received, and the effective rate of questionnaires was $87.2 \%$, of which 32 were males, and 91 were females; 23 people were majoring in pharmacy, 21 people were majoring in foreign language, 17 people were majoring in clinic and oral medicine, 25 people were majoring in nursing, 37 people were majoring in other specialties. Please refer to Table 1 for details 


\begin{tabular}{|c|c|c|c|}
\hline \multirow{3}{*}{ Gender } & & Quantity (N) & Percentage (\%) \\
\hline \multirow{3}{*}{ Specialty } & Male & 32 & 26.02 \\
\cline { 2 - 4 } & Female & 91 & 73.98 \\
\cline { 2 - 4 } & Pharmacy & 23 & 18.70 \\
\cline { 2 - 4 } & Foreign language & 21 & 17.07 \\
\cline { 2 - 4 } & Clinic and oral medicine & 17 & 13.82 \\
\cline { 2 - 4 } & Nursing & 25 & 20.33 \\
\hline
\end{tabular}

\section{B. Research tool}

The self-compiled "questionnaire for the current status of minor in double degree in Inner Mongolia Medical University" is adopted. The latitude is designed as per the literature review and its own experience. Expert method is adopted to ensure the validity of questionnaire, and the members of the task will judge the reliability for the contents of the questionnaire, and make modification as per the opinions of experts, until there are no doubts over all problems.

\section{Data processing}

SPSS22.0 is adopted to conduct descriptive statistics, and significant difference inspection.

\section{RESULTS AND ANALYSIS}

\section{A. Cognition of double degree students on double degree education}

The cognition on double degree education can influence the degree of emphasis on double degree study to a great extent. In Level 5 scale, the average comprehensive degree of investigated students considering the double degree cultivation scheme studying thereby and the double degree prospect is respectively 3.14 and 3.20, which is under a general level, and through specific investigation, it is found out that, students who know about the various conditions of double degree through the double degree course teaching in colleges can occupy $40.65 \%$, while students who know about the conditions from the department they are in can merely occupy $16.26 \%$. Besides, the average comprehensive degree of investigated students in the conditions about the double degree professional course setup studied thereby is 3.24 .

\section{B. Learning motivations for double degree students}

It can be found in Table 2 that, "studying new knowledge, and improving quality" and "promoting employment competitiveness" are the main motivation for college students to conduct double degree study, and can respectively occupy $66.29 \%$ and $77.24 \%$ of the investigated students. Both of them can drive study internally and externally, and it can be seen that, active learning motivation can drive student's active learning attitude.

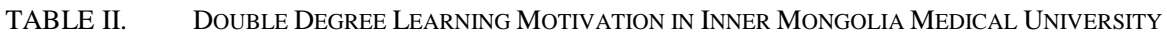

\begin{tabular}{|c|c|c|}
\hline & Quantity (N) & Percentage (\%) \\
\hline Learning new knowledge, and improving quality & 84 & 77.24 \\
\hline Improving employment competitiveness & 95 & 16.26 \\
\hline $\begin{array}{c}\text { Making preparation for postgraduate study and } \\
\text { overseas study }\end{array}$ & 20 & 15.45 \\
\hline Following the trend and the crowd & 19 & 17.07 \\
\hline Personal interest & 21 & \\
\hline
\end{tabular}

Respectively use learning motivation and various factors as dependent variables to conduct the difference inspection of gender, family monthly incomes, and major type, and it is found that gender factor has an extremely obvious difference $(\mathrm{P}<0.01)$ in learning motivation of improving employment competitiveness, and the major performance is that, when being compared with male college students, female college students concentrate more on the improvement function of double degree in employment competitiveness; meanwhile, gender factor can also possess an extremely significant difference in the learning motivation of preparing for postgraduate study and overseas study $(\mathrm{P}<0.01)$, and the performance is that female college students concentrate more on the function of double degree in the future postgraduate study and overseas study. The factor of family monthly incomes exert an obvious main effect $(\mathrm{P}<0.05)$ in the motivation of improving the employment competitiveness, and the performance is that, students with higher family monthly incomes concentrate more on using double degree to promote employment competitiveness. The major professional type possesses obvious main effect in the learning motivation of personal interest $(\mathrm{P}<0.05)$, and the specific performance is that, students majoring in foreign language can choose to study for double degree for the motivation of personal interest. 


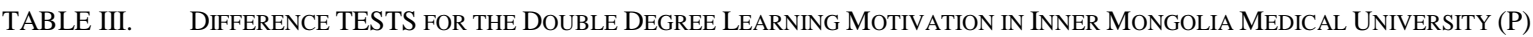

\begin{tabular}{|c|c|c|c|}
\hline & Gender & $\begin{array}{c}\text { Family monthly } \\
\text { income }\end{array}$ & Major \\
\hline $\begin{array}{c}\text { Learning new knowledge } \\
\text { Improving employment } \\
\text { competitiveness }\end{array}$ & 0.413 & 0.382 & 0.207 \\
\hline $\begin{array}{c}\text { Preparing for postgraduate study and } \\
\text { overseas study }\end{array}$ & $0.000^{*}$ & $0.038^{*}$ & 0.252 \\
\hline $\begin{array}{c}\text { Following the trend and the crowd } \\
\text { Personal interest }\end{array}$ & $0.008^{*}$ & 0.672 & 0.092 \\
\hline
\end{tabular}

C. Evaluation of students with double degree for course and teaching management

As can be seen from Table 4, the satisfaction degree of students for the specialty setup of double degree in schools is merely $41.46 \%$, and most students who are not satisfied about specialty setup hope that the school can increase specialties for double degree education, such as psychology, foreign language and other specialties. With respect to the setup of learning qualification, most students support existing conditions, which can also reflect that students with better achievements in their major can better adapt to the learning status of two specialties. The double degree courses for the investigated students are mostly set at legal holidays, winter and summer vacations, and regarding this, merely $29.27 \%$ of students agree with the current school time arrangement. However, with respect to the setup of tuition, about $49.59 \%$ students think that the double degree tuition is unreasonable.

TABLE IV. CONDITIONS ABOUt THE EVALUATION OF STUDENTS WITH DOUBLE DEGREE ON TEACHING MANAGEMENT IN INNER MongOLIA MEDICAL UNIVERSITY

\begin{tabular}{|c|c|c|c|}
\hline & Student Evaluation & Quantity (N) & Percentage (\%) \\
\hline Major setup & Satisfied & 51 & 41.46 \\
& Unsatisfied & 72 & 58.54 \\
\hline Learning qualification & Reasonable & 96 & 78.05 \\
& Unreasonable & 27 & 21.95 \\
\hline School hours & Reasonable & 36 & 29.27 \\
& Unreasonable & 78 & 70.73 \\
\hline Tuition & Reasonable & 62 & 50.41 \\
& Unreasonable & 89 & 79.59 \\
\hline Practical course setup & Requested & 17 & 13.82 \\
& Not requested & 17 & 13.82 \\
\hline
\end{tabular}

\section{Evaluation of students with double degree for the teaching}

As for the teaching evaluation of teachers, Level 5 scale is adopted for investigation, and after obtaining the average value, it can be seen from Table 5 that, students have a relatively high evaluation on the personal quality and teaching means of teachers, and the average value is respectively 4.27 and 4.32, and in the teaching process, good interaction between teachers and students can increase classroom climate, and mobilize students' thought; with respect to this point, the students' evaluation is 4.5 points. On the opposite, students' satisfaction degree for the teaching attitude of double degree courses is relatively low, which is merely 3.06 points. 

MEDICAL UNIVERSITY

\begin{tabular}{|c|c|c|}
\hline & Average Value & Standard Deviation \\
\hline Teaching attitude & 3.06 & 0.94 \\
\hline Knowledge of teachers & 4.27 & 0.60 \\
\hline Teaching means & 4.32 & 0.70 \\
\hline Interaction between teachers and students & 4.50 & 0.56 \\
\hline
\end{tabular}

\section{CONCLUSION AND SUGGESTIONS}

The minor of double degree education is an important approach for the cultivation of integrated talents and can meet the demand of the current society for graduates. The investigation about the current status of double degree education can be not only beneficial to the improvement of system and relevant measures as per the demand of students, but also be beneficial to the improvement of students' cognition on double degree education, and can help students choose double degree study to a certain degree.

\section{A. Double degree students lack reasonable guidance}

Before signing up for double degree study, due to the lack of reasonable guidance, some students make irrational decisions, and there are many students selecting double degree study due to following the trend and the crowd. In the investigation, it is found out that, students who have selected double degree study know few about the double degree cultivation scheme, course setup and prospect, which can fully indicate that, when being compared with the hot double degree learning trend, corresponding guidance and publicity are still not in place.

Besides, due to the lack of reasonable guidance, students cannot handle well the relationship between their major and the double degree specialty, and then due to the energy deficiency or the loss of interests, they will generate learning burnout and even suspend the double degree study, and this phenomenon is quite common, and it is also very common to see students mutually transmitting negative emotions privately. Double degree study heavier learning task, and students should have better adjustment capacity of their own learning status, otherwise the two specialties studied thereby will be mutually influenced. Therefore, the establishment of reasonable guidance mode can not only avoid students making irrational decisions during the registration, but also decrease the burnout sense in the studying process, and help students adjust their own status.

\section{B. Award and punishment system of double degree education is unsound}

Students have active learning motivation for double degree, but in the actual learning process, due to the lack of reasonable award and punishment system, partial students have the thought of "60 points are enough". Besides, schools are extremely loosened for the graduation conditions of double degree specialty, and merely request all courses and major to reach up to standard, which has caused students relatively low emphasis degree on courses. On the other hand, there is no various scholarships being set in double degree education, and as an important incentive measure for students, scholarship also means the recognition on the endeavors made in the course of study. Therefore, the setup of reasonable scholarship system and graduation conditions can exert an important promotion and incentive function in double degree students.

\section{Double degree specialty setting has conflicts with the demand of students}

At the beginning when double degree is established, Inner Mongolia Medical University has set the double degree of public affairs administration as per the demand of students and the conditions of each department. Through several years of development, there is no change, and some specialties with stronger application orientation or rich interests of students haven't set double degree education yet. The school shall set double degree specialties as per the external society, the school itself, the interests of students and other factors, to meet the learning demand of students, and adapt to diversified development demands.

\section{Double degree course structure is unreasonable}

As a medical university carrying out double degree education, Inner Mongolia Medical University has particularity, and the schoolwork for medical students can be relatively heavy, and as for medical and pharmacological specialties, major course education shall still be carried out at weekends, so double degree courses are basically arranged at holidays, winter and summer vacations. But on one hand, students cannot sustain long-term concentration on studying, and the degree of satisfaction for the double degree school hours is lower, on the other hand, high-strength double degree course teaching activities continuously conducted at holidays, winter and summer vacations cannot ensure the acceptability of students for these courses.

Currently, the public affairs administration double degree specialty carried out by Inner Mongolia Medical University is the discipline requesting students to possess practical experience, and practical education plays an important role in the cultivation of students, and the demand of students for practical courses is higher, but due to the restriction of conditions in all aspects, no relevant experience, and practical courses are set for double degree, and this has made the cultivation of students majoring in double degree specialties have important deficiencies. Thus, the setup of practical courses in double degree specialties is a problem that shall be settled urgently; on the other hand, the heavy major courses shall not squeeze the implement of double degree courses, and 
the school shall actively create conditions and carry out double degree courses at ordinary nights and weekends.

\section{E. Double degree teaching supervision mechanism lacks}

The state doesn't set unified specification for double degree education yet, but it has given each university the right to formulate each link specification and system, so the approaches of universities are different in double degree education, and Inner Mongolia Medical University hasn't set professional double degree teaching management department. The investigation shows that the students hold recognition attitude for the personal quality and teaching level of double degree teachers, but they think that the attitude of course teachers is general, so it is very necessary to include double degree into the supervision range of normal undergraduate education, but double degree teaching activity is generally arranged at weekends and holidays, so the school shall establish professional double degree teaching management department as per demands.

Through several years of development, double degree education has initially become valid at Inner Mongolia Medical University, but there are still partial problems being found in the investigation; double degree education not only requires the input of students themselves, but also requires the management of various links, the top design and endeavors of teaching department.

\section{ACKNOWLEDGEMENT}

About the Author: Hu Jiajing (1990-), the Teacher and Teaching Assistant for the Sanitation Management College of Inner Mongolia Medical University, and mainly studies sanitation policy, sanitation informatization and medical education;

Corresponding Author: Zhang Nan (1981- ), the Associate Professor and Doctor of for the Sanitation Management College of Inner Mongolia Medical University, and mainly studies sanitation policy, and hospital management. E-mail: skyzn@126.com.

\section{REFERENCES}

[1] Chen Xuemin, Double Degree Undergraduate Education Research, China Higher Education Research [J], 2007, (2): 26-28.

[2] Xu Penghui, Existing Problems and Countermeasures for the Minor in Double Degree Education in Medical Universities-taking Wannan Medical College as an example, Journal of Liaoning Medical University. (Social Science Edition) [J], 2016, (11): 33-36.

[3] Peng Li, Several Suggestions for Perfecting the Double Degree Undergraduate Education in Our Country, Journal of Southwest Agricultural University (Social Science Edition) [J], 2011, (5): 159-162.

[4] Xu Jinyan, Reflections on the Reform of Course Setup for Public Affairs Administration Specialty in Universities, Contemporary Education Theory and Practice [J], 2016, (3): 87-89. 